\title{
A METHOD OF OPTIMIZING FENESTRATION DESIGN FOR DAYLIGHTING TO REDUCE HEATING AND COOLING LOADS IN OFFICES
}

\author{
Hendrik VOLL, Erkki SEINRE \\ Department of Environmental Engineering, Tallinn University of Technology, \\ Ehitajate Tee 5, 19086 Tallinn, Estonia \\ Received 10 Apr 2012; accepted 18 May 2012
}

\begin{abstract}
Modern office building designs tend to increase the window share per facade to make the building more impressive with extensive visibility and well daylit rooms. In general, an increased window share results in higher energy usage and higher costs of heating and cooling, but these disadvantages can be reduced with a more careful design. The aim of this paper is to show the influence of window design and room layout on heating and cooling demand and daylight availability in office buildings in northern Europe. The results in the paper are based on design calculations for two different room types and daylight measurements on two room scale models in a daylight laboratory. The calculations show the influence of window design parameters on the cooling and heating demand. The daylight measurements show the influence of window design parameters on the availability of daylight. The results have then been combined to show a feasible window design regarding daylight availability and the resulting cooling and heating demands for different window orientations. The results show that in most cases it is possible to find a combination of window share and window solar factor that is feasible with regard to daylight as well as cooling and heating. The main finding is that there is a smaller or wider range of feasible designs for different window orientations.
\end{abstract}

Keywords: passive architectural cooling, daylight, energy efficiency, cooling load, heating load.

\section{Introduction}

Daylighting of buildings by using the diffuse rays of the sunlight as the primary light source has been given a great deal of research attention in the last 15 to 20 years. Studies by Fisk (2000) or (Veitch, Gifford 1996) or (Roche, Dewey 2000) showed the positive effects of daylight on students, shoppers and office workers health and productivity. According to Littlefair (2001) or Loveland (2003) daylit buildings seem to increase human performance, partly because people enjoy such spaces and will stay a little longer and return more frequently to their work place or, when shopping, to the shop.

Modern office building designs in northern Europe show a tendency to increase the window share per facade to make the building more impressive with extensive visibility (Šeduikyte, Paukštys 2008). In many new and large scale projects in Estonia, Latvia and Lithuania the window share has been designed to be $70 \%$ per façade or even higher. As daylight brings warmth and sparkle to architecture architects seem to be very fond of glass architecture. However according to (Boyce, Heerwagen 2006; Menzies, Wherret 2005) the so-called glass architecture may also cause extreme discomfort for building occupants and excessive energy and retrofitting costs for building owners when its potential is misused.
In general, an increased window share results in increased energy usage, with resulting costs for heating and cooling Poirazis et al. (2008) or Mustakallio (2010). The buildings have a large heating demand during the winter and when the heat from solar irradiation, people, office equipment and electrical lighting exceeds the heat loss at the highest acceptable room temperature there is a heat surplus that has to be removed. In addition, modern office buildings are well insulated, causing them to require cooling from April to the middle of September (Motuziene, Juodis 2010). There are multiple ways to decrease the cooling demand of office buildings. One method, passive architectural cooling, which includes external overhangs, smart facades, and so on, is becoming more popular and widely used Fahlen et al. (2006). Dubois (2001) analysed the annual energy use for heating and cooling of a singleoccupant office room located in Lund (Sweden) for eight solar-protective glazing options and one shading system. Various window shares and orientations were studied. The study showed that the most energy-efficient glazing option was orientation-dependent: south and north orientations required higher solar transmittance or window share than east and west ones. The study also demonstrated that a removable awning coupled with clear glazing performed better in terms of annual energy use than all the solar-protective glazing options tested. However, it 
was also demonstrated that the fixed awning resulted in higher annual energy use compared with solar-protective glazing for all orientations. This study generally shows that glazing and shading strategies should be flexible in cold climates and allow the use of solar gains during the heating season while limiting those gains during the cooling season. The study however did not include daylight analyses.

The main objective of this paper is to show the influence of design window parameters and room layouts on cooling and heating demand and daylight availability in office rooms. It is hoped that the evaluation method introduced will soon be widely used by architects in the Baltic countries. The hypothesis is that there are certain combinations of window sizes and window types that are more feasible than other combinations from an economic as well as a daylight point of view.

\section{Limitations}

The study focuses on conditions valid for latitudes of around $53 \sim 60^{\circ}$ in north and northeast European locations.

\section{Diffuse daylight parameters}

Good quality daylight should be sufficient for visual tasks, visually comfortable and perceptually pleasing, glare-free, and well distributed across the space. In other words the daylight is a combination of diffuse daylight and direct solar radiation.

Based on Estonian Standard 894, Daylight in Dwellings, it is the daylight factor that describes diffuse daylight. In general, the daylight factor is the ratio of inside illuminance to outside illuminance at a specific point, expressed as a percentage.

$$
D F=100 \times\left(E_{\text {in }} / E_{\text {out }}\right),
$$

where: $D F$ - the daylight factor, [\%]; $E_{\text {in }}$ - inside illuminance at a fixed point, [lx]; $\mathrm{E}_{\text {out }}$ - outside horizontal illuminance under an overcast sky, [lx]. In north European circumstances, spaces with a minimum daylight factor of 2 and where the difference between the highest and lowest daylight factor is below 20 are normally considered to give the room's occupant the feeling of a daylit room.

Each daylight factor depends on an $\mathrm{lx}$ value. The recommended $\mathrm{lx}$ illuminance standards vary between different activities, types of spaces, and countries. Slater (1998) proposes that any daylight illuminance in the range of 100-2000 lx should be considered as offering potentially useful illumination for the occupants in the space. An illuminance level of $300 \mathrm{~lx}$, however, seems to be the average standard minimum value for office room work zones in different countries (Schuler 1995).

Glare is defined as difficulty seeing in the presence of bright light that may be caused by either direct or indirect viewing of a light source (O'Connor 1998). Direct glare is caused by light coming directly to the eye from a light source. Indirect glare is light reflected from a surface in the direction of the eye. Here, glare caused by a large contrast between the highest and lowest illuminance levels in the room and glare from direct sunlight reflect- ing off a glass surface are investigated. Too much contrast makes a room feel gloomy and annoys, distracts, or reduces visibility, and sunlight reflections may cause exaggerated lighting.

\section{Input data for the analysis}

Figure 1 presents the two office room layouts used in the cooling and heating power demand simulations and the daylight availability tests.
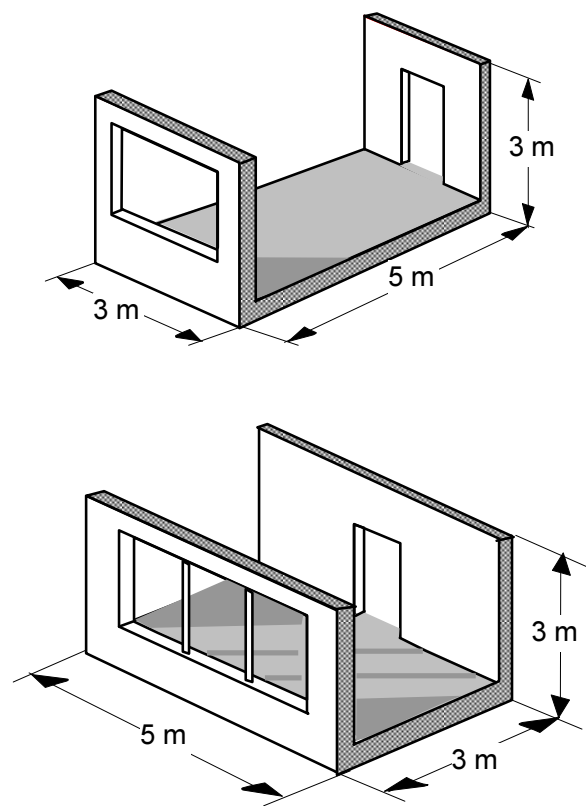

Fig. 1. Top: room type 1; bottom: room type 2

The solar factor $g$ is the ratio of solar heat gain through a glazing to solar heat gain through a single clear glass. The smaller the number, the better the glazing is at preventing solar heat gains but the poorer it is at allowing natural daylight to enter the room (Bergsten 2004).

In office room simulations the following values were used: heat transmission coefficient (U-values): facade wall $0.27 \mathrm{~W} /\left(\mathrm{m}^{2} . \mathrm{K}\right)$, window $1.2 \mathrm{~W} /\left(\mathrm{m}^{2} . \mathrm{K}\right)$, and ceiling $0.15 \mathrm{~W} /\left(\mathrm{m}^{2} . \mathrm{K}\right)$; installed lighting power $10 \mathrm{~W} / \mathrm{m}^{2}$; office equipment $10 \mathrm{~W} / \mathrm{m}^{2}$; and people $6 \mathrm{~W} / \mathrm{m}^{2}$, infiltration rate $0.18 \mathrm{1} / \mathrm{h}$. It is presupposed that the room temperature is not allowed to exceed $+25^{\circ} \mathrm{C}$ during more than 80 working hours per year.

\section{Diffuse daylight tests}

Tests conducted at Tallinn University of Technology (TUT) daylighting laboratory show how different solar factors and window sizes influence the daylight availability inside a type 1 or 2 office room. The daylighting lab in Tallinn has a mirror-box overcast sky for the analysis of physical scale models at all stages of the design process (Fig. 2).

The mirror-box overcast sky conforms to the "international overcast sky" Voll et al. (2011). The shadowless artificial overcast sky condition created in the mirror-box is a test condition defined by the International Commission of Illumination (CIE). 


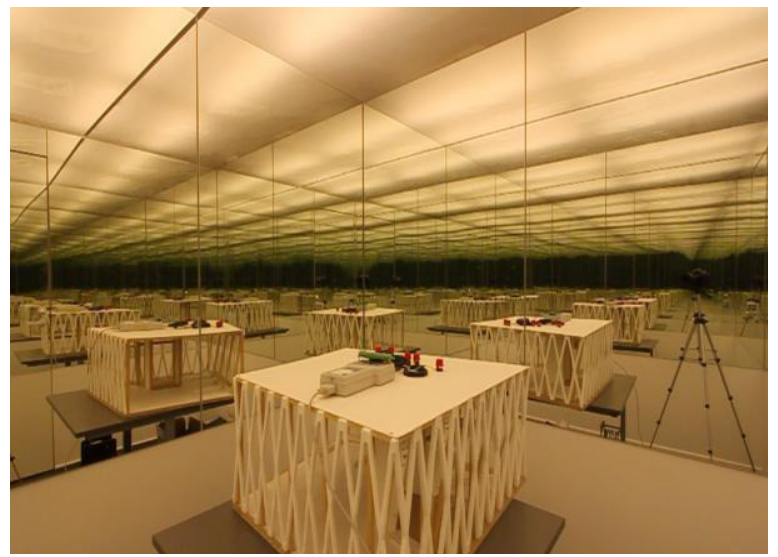

Fig. 2. Overcast sky simulator interior view

The models of room types 1 and 2 were built and tested at a scale of 1:10 in relation to the original size, with interchangeable parts to test multiple floor and facade alternatives. For both room types, four different facade layouts with window (glass) areas of $30 \%, 50 \%$, and $80 \%$ were studied. Six photocells were used to measure the percentage of available daylight in overcast conditions. One "control cell" was placed on top of the model oriented towards the zenith to measure the amount of available daylight. Inside the model, five photocells were placed at work zone height $(0.85 \mathrm{~m}$ on the original scale $)$ to measure the amount of light reaching the interior. The photocells inside the room were moved to different positions parallel with the window facade. For both room types and each window glass area, 50 daylight factor readings were taken.

Figure 3 shows the results for both room types; to fulfil the requirements, the daylight factor should be 2 or above and the difference between the highest and lowest daylight factor should be below 20. If these requirements are to be met, the window glass share and solar factor combination must lie within the marked light grey area. The hatched area below that area labelled as "dark" means the lowest daylight factor in the room would be below 2. The area labelled as "gloomy" means the contrast between the lowest and highest daylight factors exceeds 20 . Thus the line separating the "daylit" area from the "dark" area shows the minimum possible combinations of window glass share and solar factor that fulfil the daylight requirements.

The line separating the "daylit" and "gloomy" areas shows the limits of possible combinations of window glass share and solar factor that fulfil the diffuse daylight requirements without risk of creating a gloomy space.

\section{Tests of daylight window}

Motivated by the study accomplished by Dubois (2001) in which she analysed the annual energy use for heating and cooling of a single-occupant office room located in Lund (Sweden) for eight solar-protective glazing options and one shading system but not for daylight, a passive architectural cooling method, the daylight window, has been tested in this work. To study the effectiveness of daylight windows in north European circumstances, a daylight window in both room types was designed and tested in parallel with the ordinary window (here referred as window with no external shading or internal lightshelf) for daylight and for cooling and heating loads.
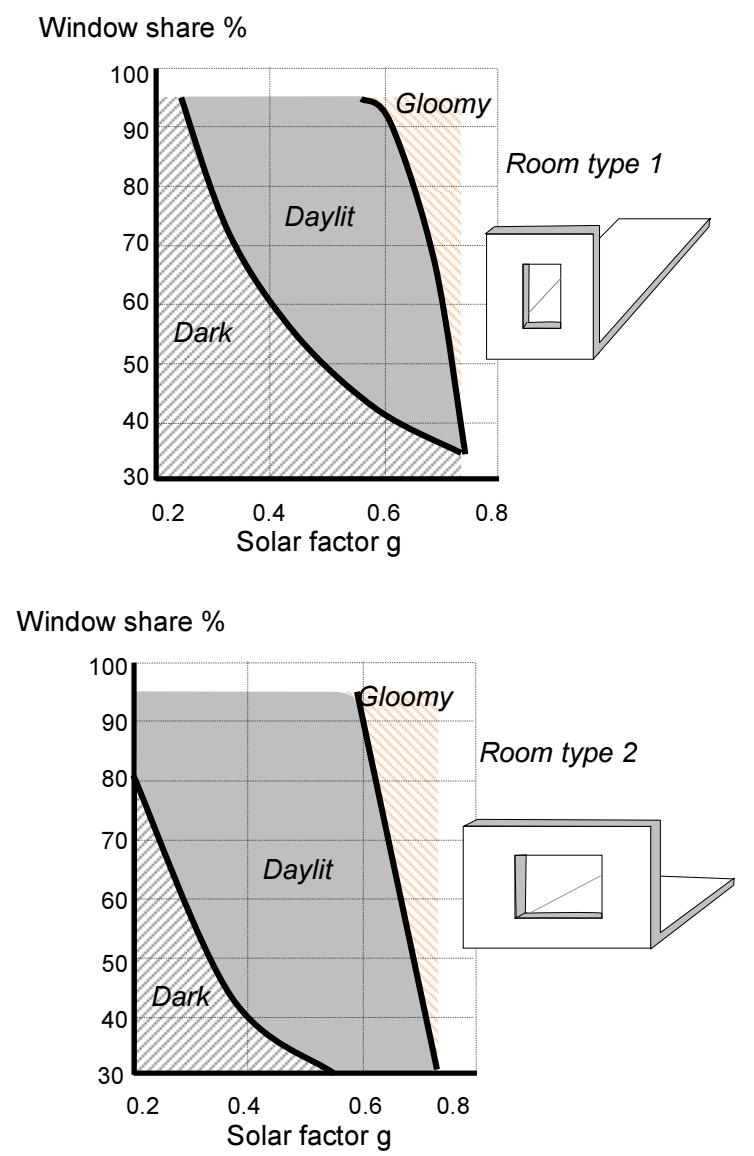

Fig. 3. Possible window glass share and solar factor combinations that fulfil the requirements: The daylight factor should be 2 or above and the difference between the lowest and highest daylight factors must not exceed 20 . The result is valid for all orientations

The daylight window was tested at TUT daylighting lab's heliodon table. The heliodon table shown in Figure 4 is comprised of a tilting/rotating table (the earth) and a stationary 1000 watt theatrical light source (the sun). The table can be adjusted to represent the latitude, tilted to simulate any month of the year, and rotated to analyse any time of day.

A daylight window is basically a window that has an exterior overhang and interior lightshelf design, see Figure 5.

The width of the exterior overhang (no. 3 on Fig. 5) and interior lightshelf (no. 4 on Fig. 5) is normally equal to the width of the daylight and viewing window (nos. 5 and 6 on Fig. 5). The length of the exterior overhang is normally equal to the height of the viewing window. The length of the interior lightshelf is normally equal to the height of the daylight window.

1. Daylight Window: high performance glazing with a low solar factor of 0.4 or less. In this paper the solar factor was taken as 0.2 for all tests. 


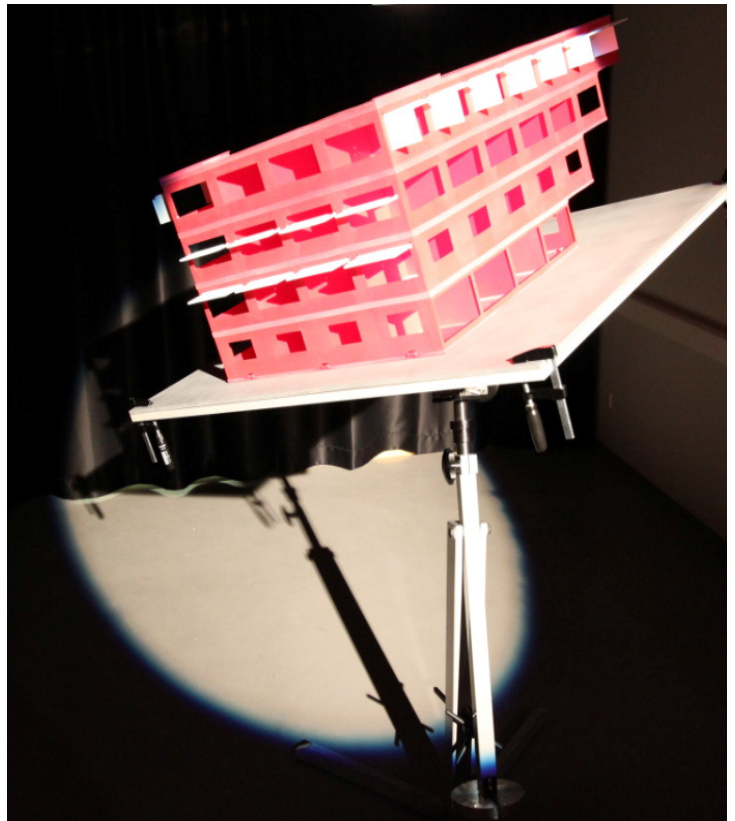

Fig. 4. Heliodon table at TUT daylighting laboratory

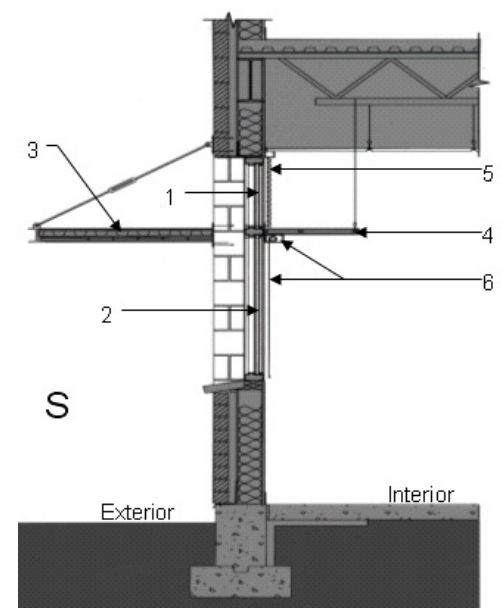

Fig. 5. The concept of a daylight window

2. Viewing Window: solar factor of 0.7 or lower. For tests described in this paper the viewing window was tested with solar factors of $0.4,0.6$, and 0.7 .

3. Exterior Overhang: this can be almost any material depending on the architectural resources and/or location of the building (snowy or non-snowy climates). Common material choices include panel systems, metal grating, tempered translucent glass, and polycarbonates.

4. Interior Lightshelf: this is often made of painted plywood, gypsum board, perforated metal, or translucent glass. It is crucial that the upper surface be matt-finish white.

5. Louvre Blind: horizontal adjustable louvre blinds are very common. They range between very inexpensive standard aluminium louvres to highly engineered specialty louvre systems.

According to Voll et al. (2011), in Nordic conditions horizontal shading is the most effective for blocking the glare and direct solar access for the south orientation.
For that reason the cooling load tests for daylight windows were carried out only for the south orientation and not for other orientations. Daylight and heating load tests are not influenced by the orientation.

Figures 6 and 7 show the results for rooms 1 and 2, respectively, when they are equipped with a daylight window to fulfil the requirement for a daylight factor of 2 or above ( $\mathrm{DF} \geq 2)$. If this requirement is to be fulfilled, the window glass share and solar factor combination must lie within the marked areas.

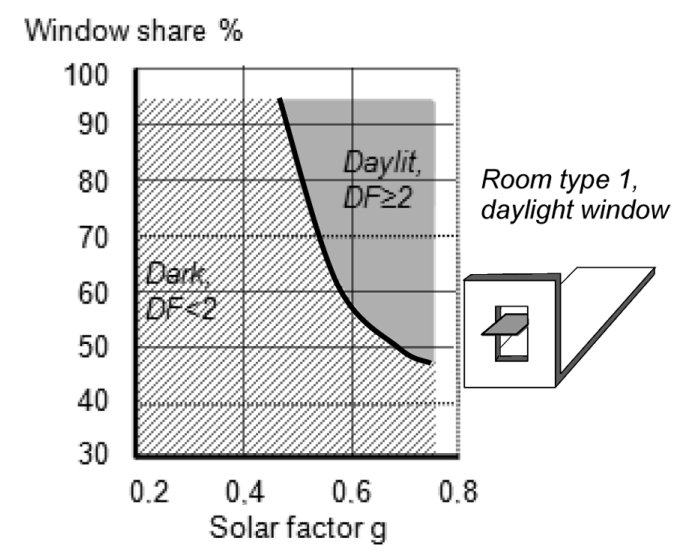

Fig. 6. Possible combinations of window glass share and solar factor for room type 1 that meet the requirement for a daylight factor $(\mathrm{DF}) \geq 2$

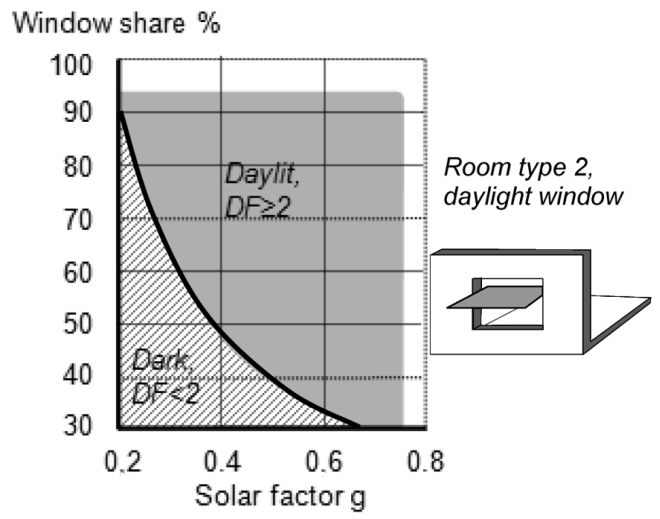

Fig. 7. Possible combinations of window glass share and solar factor for room type 2 that meet the requirement for a daylight factor $(\mathrm{DF}) \geq 2$

Figures 8 and 9 show a comparison of the results for the daylight window and an ordinary window for rooms 1 and 2, respectively. The light grey area in the figures represents the daylit area (where the daylight factor is 2 or above) for the daylight window and the area enclosed by a dotted line is the daylit area given by the ordinary window.

According to the measurement results the daylight window spreads the daylight inside the room more equally compared to the ordinary window. A daylight window helps to smooth out the interior daylight distribution. The difference between the lowest and highest daylight factors in the room is lower than for the ordinary window. The shallower the room and the larger the glass area, the more beneficial the daylight window becomes. Also, 
there is usually no risk of creating a gloomy space when a daylight window is used.

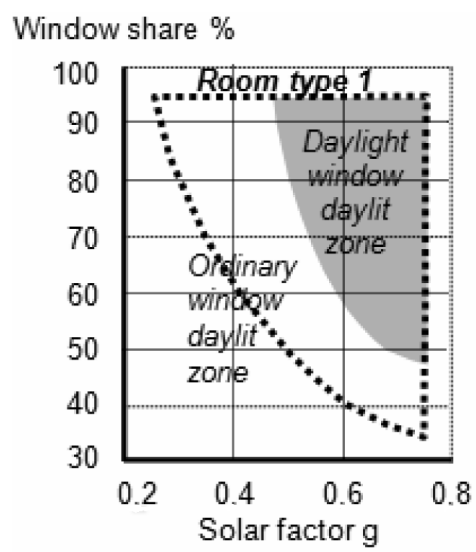

Fig. 8. Possible combinations of window glass share and solar factor that fulfil the requirement for a daylight factor of 2 or above, comparing ordinary and daylight windows

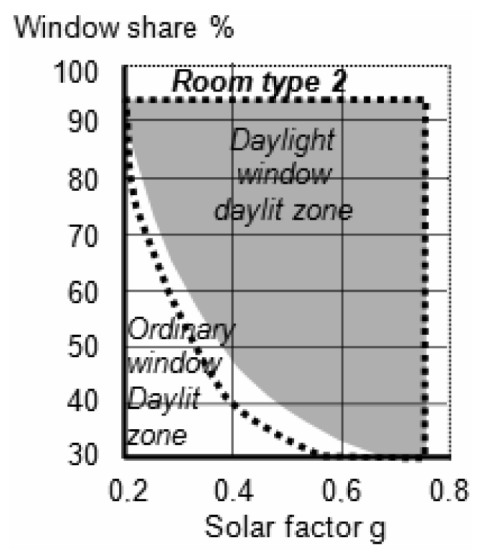

Fig. 9. Possible combinations of window glass share and solar factor that fulfil the requirement for a daylight factor of 2 or above, comparing ordinary and daylight windows

\section{Simulation of cooling demand}

Figures 10 and 11 show the possible window shares for different maximum cooling power demands $(50,75$ and $100 \mathrm{~W} / \mathrm{m}^{2}$ ) as a function of the solar factor for room types 1 and 2, respectively with north, east, west and south orientations. Tests were conducted with the well-defined simulation software IDAice (Tark 2010). The lines in Figures 4 and 5 show the relation between the window share and the solar factor resulting in the same maximum cooling power demand. This relation, in the form of the product, is in most cases close to a constant value. This means, for example, that a combination with $60 \%$ window share and a solar factor of 0.4 will give a quite similar cooling power demand to a $40 \%$ window share with a solar factor of 0.6 , as the product of the two is the same in both cases.
Window share $\%$

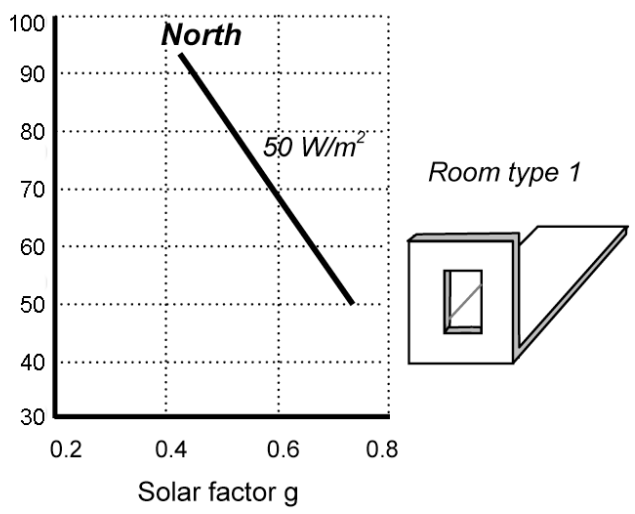

Window share \%

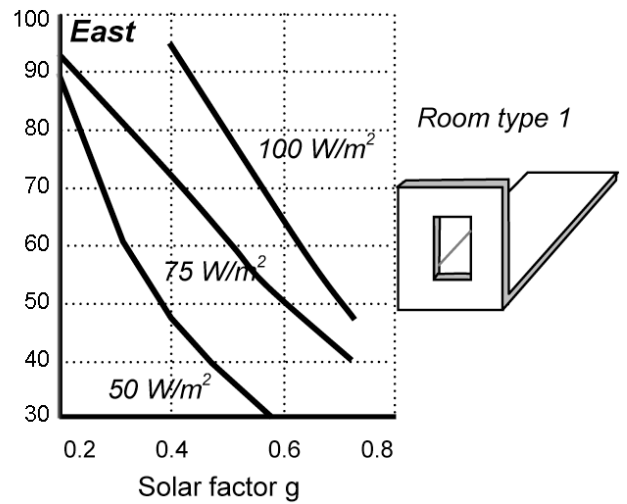

Window share \%

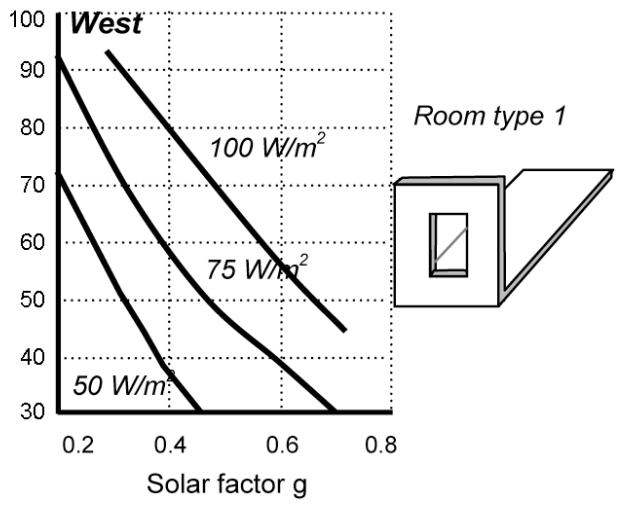

Window share \%

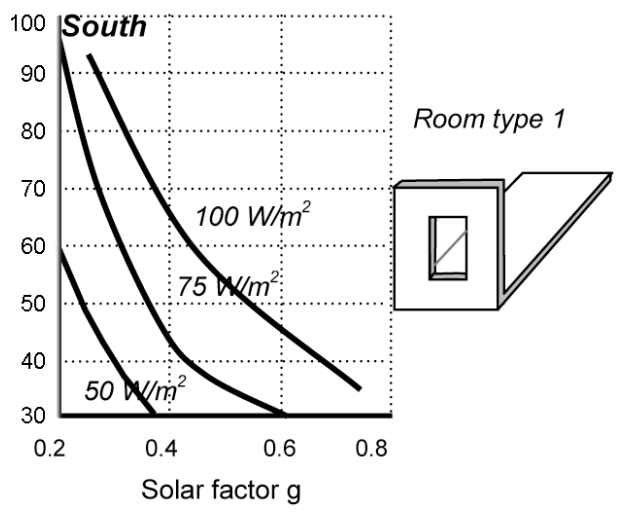

Fig. 10. Possible combinations of window glass share and solar factor for room type 1 for a maximum cooling power demand of 50,75 , or $100 \mathrm{~W} / \mathrm{m}^{2}$ 


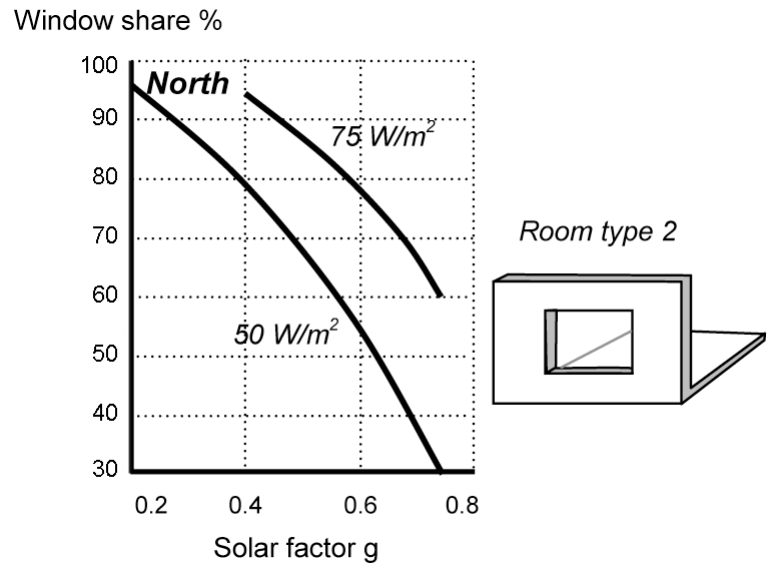

Window share \%

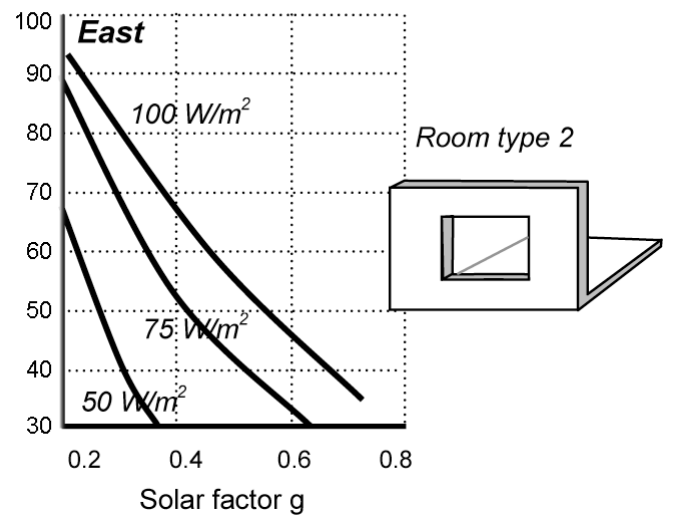

Window share $\%$

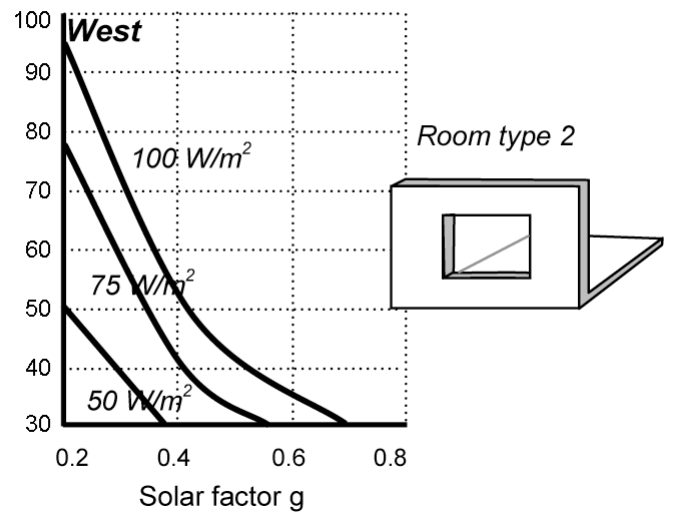

Window share \%

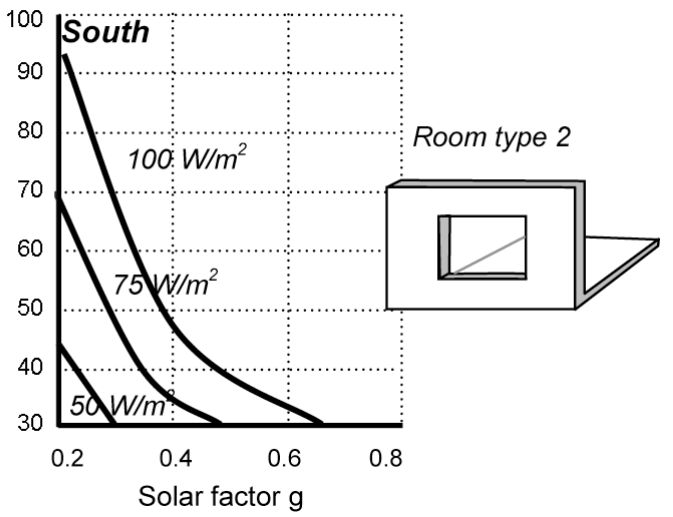

Fig. 11. Possible combinations of window glass share and solar factor for room type 2 for a maximum cooling power demand of 50,75 , or $100 \mathrm{~W} / \mathrm{m}^{2}$
For north orientations the product of window share and solar factor for a certain maximum cooling power demand could be much larger compared to all other orientations. The south orientation has the highest maximum solar irradiation in both $\mathrm{W} / \mathrm{m}^{2}$ and $\mathrm{Wh} / \mathrm{m}^{2}$ and therefore results in the highest cooling demands. South orientations therefore require a careful choice of window glass area and solar factor. The combinations of window glass share and solar factor that are feasible for east and/or west facades are between the values for north and south facades.

Figures 12 and 13 show the possible window shares for different maximum cooling power demands $(50,75$ and $100 \mathrm{~W} / \mathrm{m}^{2}$ ) as a function of solar factor for room types 1 and 2, respectively for south orientations with a daylight window.

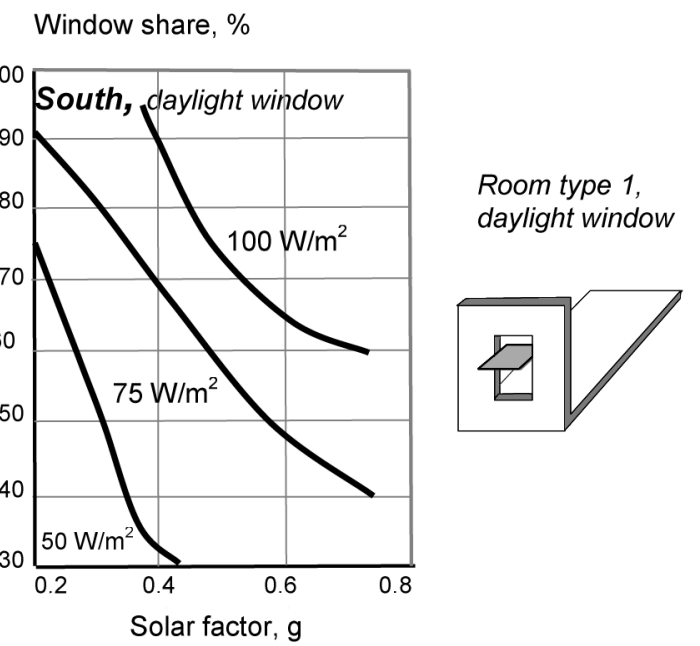

Fig. 12. Possible combinations of window glass share and solar factor for room type 1 with a daylight window for maximum cooling power demand of 50,75 , or $100 \mathrm{~W} / \mathrm{m}^{2}$

\section{Window share, $\%$}

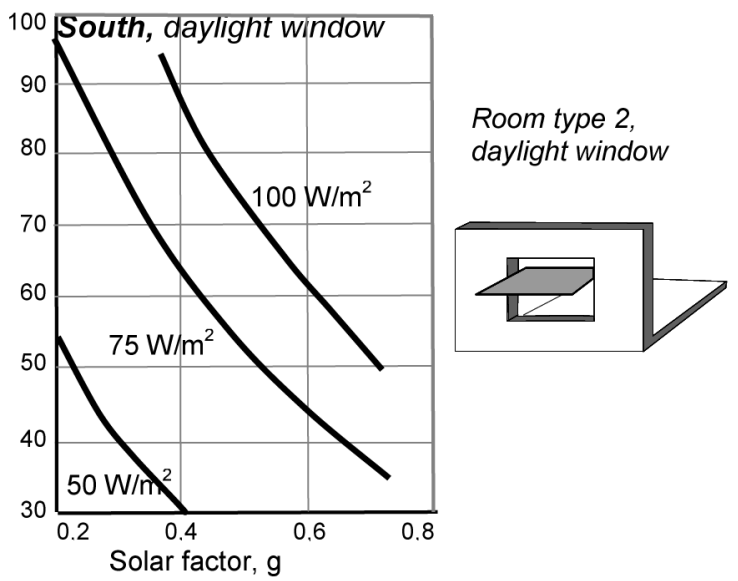

Fig. 13. Possible combinations of window glass share and solar factor for room type 1 with a daylight window for a maximum cooling power demand of 50,75 , or $100 \mathrm{~W} / \mathrm{m}^{2}$

In the case of a daylight window for south orientations, the cooling power demand is decreased compared to an ordinary window and it is possible to use larger window shares without increasing the cooling power demand. 


\section{Simulation of Heating Demand}

Figures 14 and 15 show the possible window shares for different maximum heating power demands (25 or $30 \mathrm{~W} / \mathrm{m}^{2}$ ) as a function of solar factor and $\mathrm{U}$-value for room types 1 and 2 , respectively. Heating set point temperature was taken $2{ }^{\circ} \mathrm{C}$ rest of the input data is presented in chapter 4, "INPUT DATA FOR THE ANALYSIS".

The lines in Figures 14 and 15 show the window share resulting in the same maximum heating power demand. The results are not dependent on the orientation of the room, since the lowest heating demand occurs at night when no solar irradiation occurs, nor are they influenced by the construction of the daylight window.

Window share, $\%$

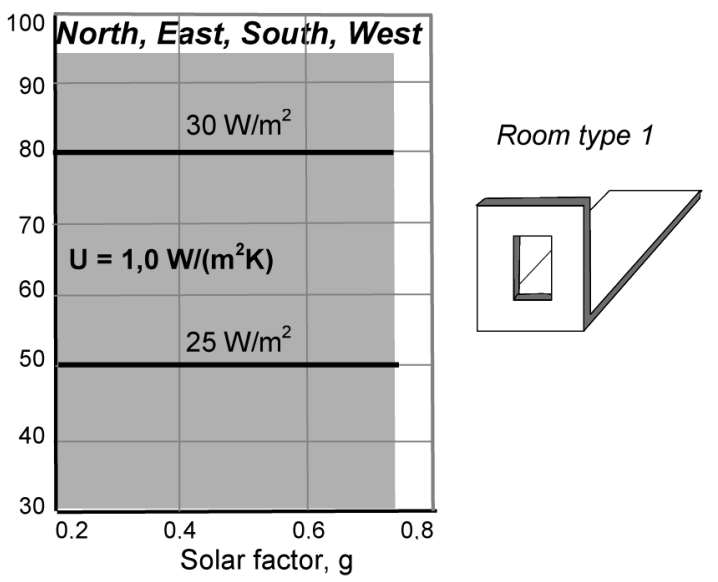

Fig. 14. Possible combinations of window glass share and solar factor for room type 1 for a maximum heating power demand of 25 or $30 \mathrm{~W} / \mathrm{m}^{2}$

Window share, \%

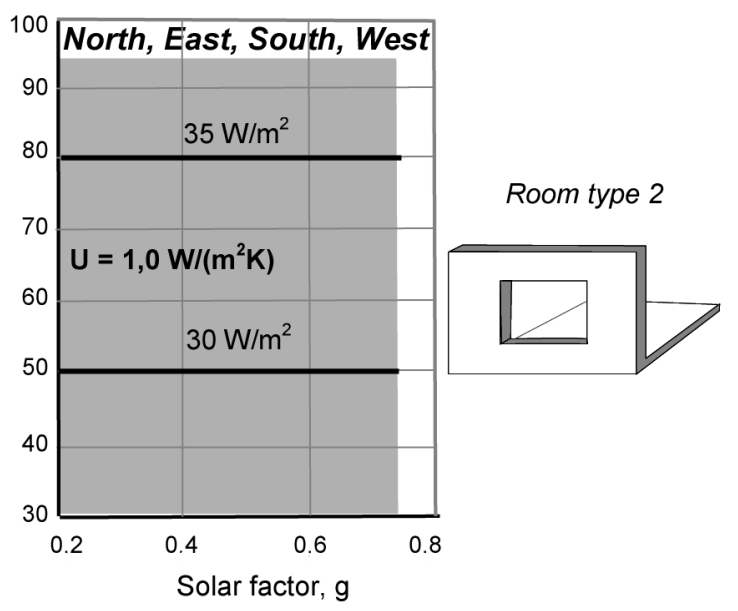

Fig. 15. Possible combinations of window glass share and solar factor for room type 2 for a maximum heating power demand of 30 or $35 \mathrm{~W} / \mathrm{m}^{2}$

\section{Results}

Figures 17 and 18 show the possible combinations of window glass share and solar factor for office types 1 and 2 , respectively, that fulfil all four requirements: the cooling power demand is below $100 \mathrm{~W} / \mathrm{m}^{2}$, heating power demand is below $30 \mathrm{~W} / \mathrm{m}^{2}$, the daylight factor is above 2 , and the difference between the highest and lowest daylight factors is less than 20 .

Figure 16 explains the meaning of the different areas in Figures 17 and 18. If all the requirements are to be fulfilled, the window share and solar factor combination must lie within the marked grey area labelled as "OK" in Figures 17 and 18. Combinations below the grey area have $\mathrm{DF}<2$ indicating that the minimum daylight factor is below 2 and therefore the room will be "dark". The area labelled as "gloomy" means the difference between the highest and lowest daylight factors is more than 20 Combinations above the grey area have either a cooling power demand above $100 \mathrm{~W} / \mathrm{m}^{2}$ or heating power demand above $30 \mathrm{~W} / \mathrm{m}^{2}$.

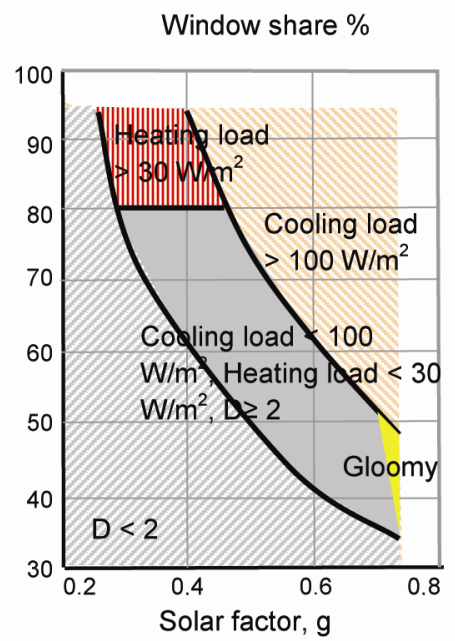

Fig. 16. Possible combinations of window glass share and solar factor that fulfil the requirements of a cooling power demand below $100 \mathrm{~W} / \mathrm{m}^{2}$, a heating power demand below $30 \mathrm{~W} / \mathrm{m}^{2}$, a daylight factor above 2 , and a difference between the highest and lowest daylight factors of less than 20

As can be seen from Figures 17 and 18, the daylight requirements - that is, a daylight factor of 2 or above and a difference between the highest and lowest daylight factors in the room of less than 20 - give the lowest feasible product of window size and solar factor. Also, a window share as low as $35 \%$ per facade for room type 1 or even lower for room type 2 can fulfil the minimum daylight requirements. The highest feasible product of window share and solar factor is decided by the maximum cooling power demand or maximum heating power demand, depending on which requirement is more strict. It can also be concluded that the risk of creating a gloomy room is normally avoided by meeting the requirements for heating or cooling loads that prevent the use of larger window shares, poor solar factors, or combinations of both. 

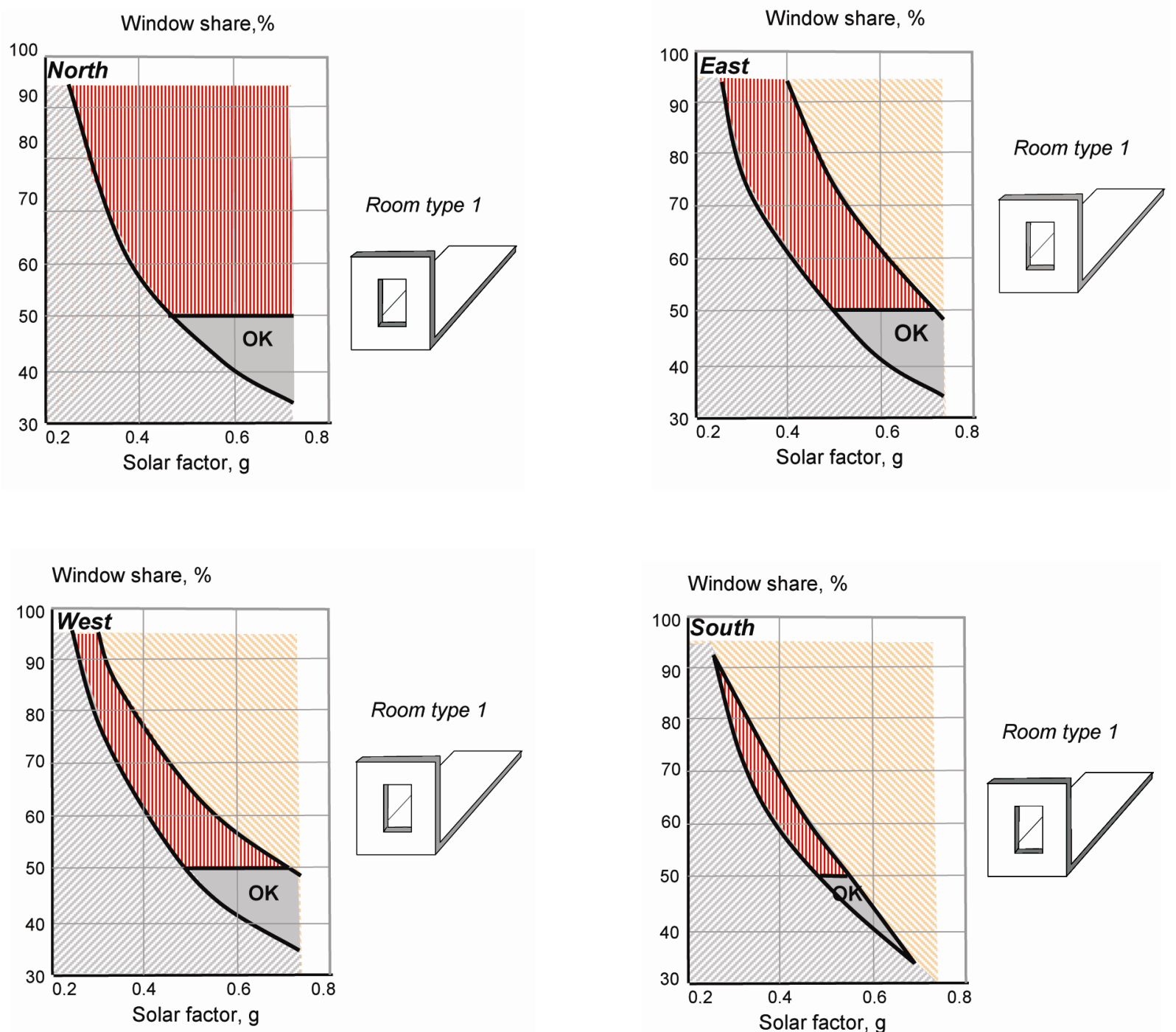

Window share, \%

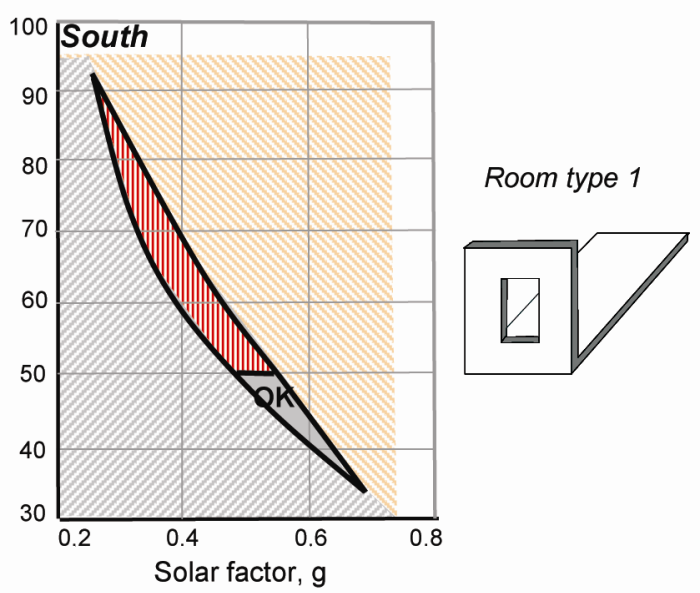

Fig. 17. Possible combinations of window glass share and solar factor for room type 1 that fulfil the requirements for a cooling power demand below $100 \mathrm{~W} / \mathrm{m}^{2}$, a heating power demand below $30 \mathrm{~W} / \mathrm{m}^{2}$, a daylight factor above 2 , and a difference between the highest and lowest daylight factors of less than 20 . Glass $\mathrm{U}$-value $=1.2 \mathrm{~W} /\left(\mathrm{m}^{2} \mathrm{~K}\right)$

\section{Discussion and conclusions}

The aim of this paper is to show the influence of window design and room layout on HVAC demand and daylight availability in office buildings in northern European conditions.

The study was carried out for two room types, both with $15 \mathrm{~m}^{2}$ of floor area, where type 1 was a rather typical office module with $9 \mathrm{~m}^{2}$ of facade area and type 2 was an office module with $15 \mathrm{~m}^{2}$ of facade area.

The study presents an enhanced background and sets out a straightforward method of analysis for use by architects in evaluating façade design and avoiding designs with extreme heating and/or cooling power demands and poor daylight conditions. It shows that a "daylit" design does not necessarily require an extremely high window share per facade. In some circumstances even a window share of $25-35 \%$ per facade could fulfil the daylight requirements. The results show that, in most cases, it is possible to find a combination of window share and window solar factor that is feasible with regards to daylight as well as cooling and heating. It also shows the advantages of using a daylight window for south facing rooms. Since every project is unique the paper did not present any exact numerical saving values for heating or cooling.

\section{Acknowledgements}

The present work was supported by EU Social Fund project number MOJD 107. 
Window share, \%

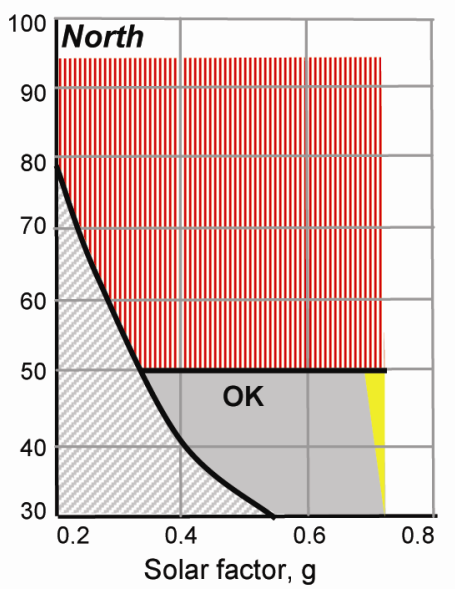

Window share, \%

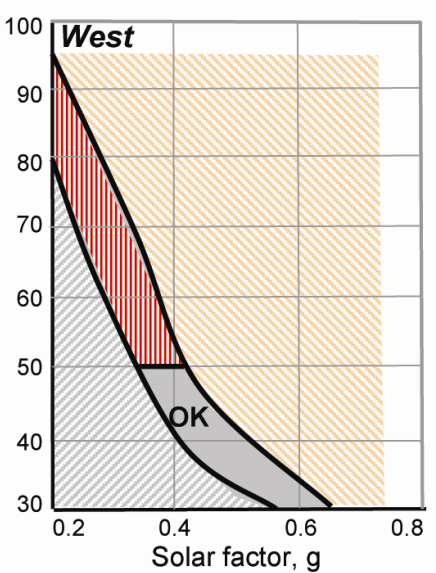

Room type 2

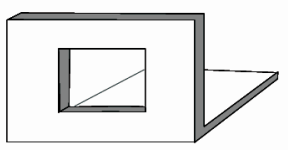

Room type 2

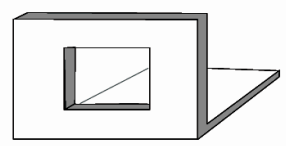

Window share, \%

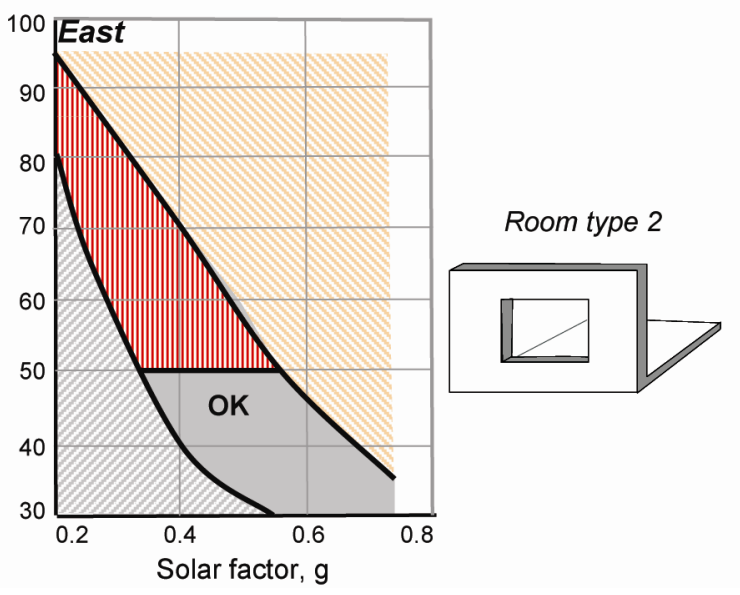

Window share, \%

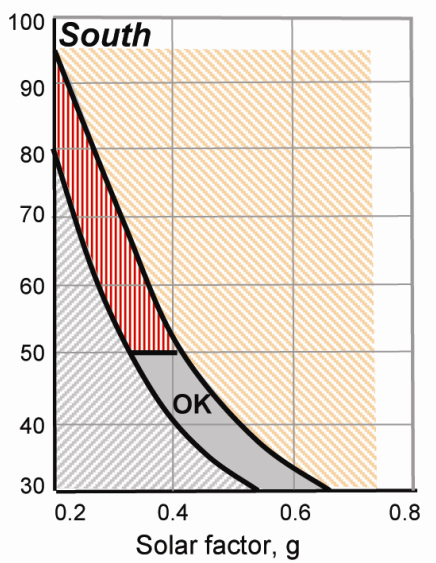

Room type 2

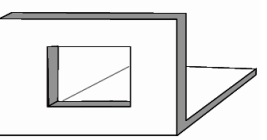

Window share. \%

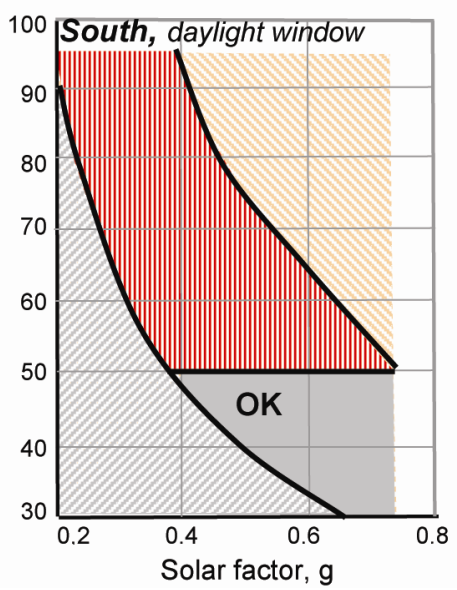

Room type 2 ,

daylight window

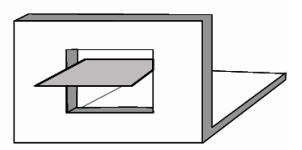

Fig. 18. Possible combinations of window glass share and solar factor for room type 1 that fulfil the requirements for a cooling power demand below $100 \mathrm{~W} / \mathrm{m}^{2}$, a heating power demand below $30 \mathrm{~W} / \mathrm{m}^{2}$, a daylight factor above 2 , and a difference between the highest and lowest daylight factors of less than 20 . Glass $U$-value $=1.2 \mathrm{~W} /\left(\mathrm{m}^{2} \mathrm{~K}\right)$ 


\section{References}

Bergsten, B. 2004. Free cooling in commercial buildings. Chalmers University of Technology Department of Building Technology, Göteborg. 198 p.

Boyce, P.; Heerwagen, J. 2006. Lighting quality and office work: two field simulation experiments, Lighting Research and Technology 38(3): 191-223. http://dx.doi.org/10.1191/13657828061rt161oa

Dubois, M. 2001. Awning and solar-protective glazing for efficient energy use in cold climates, in Conference Paper for the Renewable Energy Technologies in Cold Climates, 4-6 May, 2001, Montreal. 6 p.

EVS 894: 2008. Daylight in dwellings. Estonian centre for standardisation, Tallinn, 2008.

Fahlén, P.; Voll, H.; Naumov, J. 2006. Efficiency of hydronic heating and cooling systems, Journal of Civil Engineering and Management 12(1): 57-62.

Fisk, J. 2000. Health and productivity gains better indoor environment, Annual Review of Engineering and the Environment 25: 537-566. http://dx.doi.org/10.1146/annurev.energy.25.1.537

Littlefair, P. 2001. Daylight, sunlight and solar gain in the urban environment, Journal of Solar Energy 70(3): 177-185. http://dx.doi.org/10.1016/S0038-092X(00)00099-2

Loveland, J. 2003. Daylight by design, lightingdesign + application, Magazine of the Illuminating Engineering Society of North America 16(2): 54-62.

Menzies, G. F.; Wherrett, J. R. 2005. Windows in the workplace: examining issues of the environmental sustainability and occupant comfort in the selection of multi-glazed windows, Energy and Buildings 37(6): 623-630. http://dx.doi.org/10.1016/j.enbuild.2004.09.012

Motuziene, V.; Juodis, E. 2010. Simulation based complex energy assessment of office building fenestration, Journal of Civil Engineering and Management 16(3): 345-351. http://dx.doi.org/10.3846/jcem.2010.39

Mustakallio, P. 2010. Sustainable office building: how good energy efficiency can be achieved with modern technology in different climate conditions, in Proceedings of the
SB10 Finland, Sustainable Community-building SMART Conference Proceedings, 45-51.

O'Connor, J. 1998. Tips for daylighting with windows. Berkeley national laboratory, University of California, Berkeley, CA. 107 p.

Poirazis, H.; Blomsterberg, A; Wall, M. 2008. Energy simulations for glazed office buildings in Sweden, Energy and Buildings 40: 1161-1170. http://dx.doi.org/10.1016/j.enbuild.2007.10.011

Roche, L.; Dewey, E. 2000. Occupant reactions to daylight offices, Lighting Research and Technology 32(3): 119126. http://dx.doi.org/10.1177/096032710003200303

Schuler, M. 1995. Building simulation in application: developing concepts for low energy buildings through a cooperation between architect and engineer, in Proceedings of the Solar World Congress, the International Solar Energy Society (ISES), Harare, Zimbabwe.

Šeduikyte, L.; Paukštys, V. 2008. Evaluation of indoor environment conditions in offices located in buildings with large glazed areas, Journal of Civil Engineering and Management 14(1): 39-44. http://dx.doi.org/10.3846/1392-3730.2008.14.39-44

Slater, A. 1998. A field study of lighting levels in offices, in Proceedings of the CIBSE National Lighting Conference, London, UK, 23-33.

Tark, T. 2010. Comparison of alternative simulation software. Report Tallinn University of Technology, 66-93.

Veitch, J.; Gifford, R. 1996. Assessing lighting effects on health, performance, mood, and social behaviour, Journal of Environment and Behaviour 28(4): 446-470. http://dx.doi.org/10.1177/0013916596284002

Voll, H.; Kõiv, T.-A.; Tark, T.; Sergejeva, M. 2011. Cooling demand in commercial buildings - the influence of daylight window design, WSEAS Transactions on Applied and Theoretical Mechanics 1(5): 101-111.

Voll, H.; Seinre, E. 2011. Evaluation and comparison of various calculation zone analysis for dynamic simulation software's, International Journal of Mathematics and Computers in Simulation 20(419): 54-64.

Hendrik VOLL. Associate Professor at Tallinn University of Technology (TUT), Faculty of Construction, Department of Environmental Engineering, Chair of Heating and Ventilation. Founder of TUT Energy and Indoor Climate Laboratory. Membership: Estonian Heating Ventilation and Air Conditioning Association (member of the board). Publications: author and co-author of 1 book and over 30 research papers. Research interests include heating, cooling, ventilation, daylight, indoor climate, energy efficiency in buildings, integrated design.

Erkki SEINRE. PhD student at Tallinn University of Technology (TUT), Faculty of Construction, Department of Environmental Engineering, Chair of Heating and Ventilation (since 2009). Membership: Estonian Heating Ventilation and Air Conditioning Association. Publications: author and co-author of 6 research papers. Research interests include heating, cooling, ventilation, indoor climate, energy efficiency in buildings, building labelling. 